Article

\title{
Fabrication of Well-Aligned ZnO Nanorods Using a Composite Seed Layer of ZnO Nanoparticles and Chitosan Polymer
}

\author{
Kimleang Khun ${ }^{1}{ }^{*}$, Zafar Hussain Ibupoto ${ }^{1}$, Mohamad S. AlSalhi ${ }^{2,3}$, Muhammad Atif ${ }^{3}$, \\ Anees A. Ansari ${ }^{4}$ and Magnus Willander ${ }^{1,3}$
}

1 Physical Electronics and Nanotechnology Division, Department of Science and Technology, Campus Norkkoping, Linkoping University, Norrkoping SE-60174, Sweden; E-Mails: zafar.hussain.ibupoto@liu.se (Z.H.I.); magnus.willander@liu.se (M.W.)

2 Research Chair for Laser Diagnosis of Cancer, King Saud University, Riyadh 11451, Saudi Arabia; E-Mail: malsalhi@ksu.edu.sa

3 Physics and Astronomy Department, College of Science, King Saud University, Riyadh 11451, Saudi Arabia; E-Mails: atifhull@gmail.com

4 King Abdullah Institute for Nanotechnology, King Saud University, Riyadh, 11451, Saudi Arabia; E-Mail: aneesaansari@gmail.com

* Author to whom correspondence should be addressed; E-Mail: kimleang.khun@liu.se; Tel.: +46-011-363-119; Fax: +46-011-363-270.

Received: 8 August 2013; in revised form: 9 September 2013 / Accepted: 22 September 2013 Published: 30 September 2013

\begin{abstract}
In this study, by taking the advantage of both inorganic $\mathrm{ZnO}$ nanoparticles and the organic material chitosan as a composite seed layer, we have fabricated well-aligned $\mathrm{ZnO}$ nanorods on a gold-coated glass substrate using the hydrothermal growth method. The $\mathrm{ZnO}$ nanoparticles were characterized by the Raman spectroscopic techniques, which showed the nanocrystalline phase of the $\mathrm{ZnO}$ nanoparticles. Different composites of $\mathrm{ZnO}$ nanoparticles and chitosan were prepared and used as a seed layer for the fabrication of well-aligned $\mathrm{ZnO}$ nanorods. Field emission scanning electron microscopy, energy dispersive X-ray, high-resolution transmission electron microscopy, X-ray diffraction, and infrared reflection absorption spectroscopic techniques were utilized for the structural characterization of the $\mathrm{ZnO}$ nanoparticles/chitosan seed layer-coated $\mathrm{ZnO}$ nanorods on a gold-coated glass substrate. This study has shown that the $\mathrm{ZnO}$ nanorods are well-aligned, uniform, and dense, exhibit the wurtzite hexagonal structure, and are perpendicularly oriented to the substrate. Moreover, the $\mathrm{ZnO}$ nanorods are only composed of $\mathrm{Zn}$ and $\mathrm{O}$ atoms. An optical study was also carried out for the $\mathrm{ZnO}$ nanoparticles/chitosan seed
\end{abstract}


layer-coated $\mathrm{ZnO}$ nanorods, and the obtained results have shown that the fabricated $\mathrm{ZnO}$ nanorods exhibit good crystal quality. This study has provided a cheap fabrication method for the controlled morphology and good alignment of $\mathrm{ZnO}$ nanorods, which is of high demand for enhancing the working performance of optoelectronic devices.

Keywords: $\mathrm{ZnO}$ nanoparticles; chitosan; $\mathrm{ZnO}$ nanorods; well-aligned; low-temperature growth

\section{Introduction}

Among several compound semiconductors, $\mathrm{ZnO}$ is widely used in the development of optoelectronic devices due to its versatile properties, such as a wide direct bad gap of $3.37 \mathrm{eV}$ at room temperature, a high exciton binding energy of $60 \mathrm{meV}$, an optical grain of approximately $300 \mathrm{~cm}^{-1}$ and high mechanical and thermal stability. Recently, one-dimensional $\mathrm{ZnO}$ nanostructure has received much focus. The controlled morphology, growth parameters and physical properties of these structures are being intensely discussed by the researchers. Extensive efforts have been made to control the morphology and methods to achieve better alignment and well-controlled morphology of $\mathrm{ZnO}$ nanostructures [1]. $\mathrm{ZnO}$ has been widely used in several applications such as in catalysis [2], Gratzel-type solar cells [3], short-wavelength light-emitting devices [4,5], transparent conductors [6], chemical sensors [7], and piezoelectric nanomaterials [8]. The use of well-aligned $\mathrm{ZnO}$ nanorods in the development of a UV laser [9] has strongly motivated researchers to study the alignment of $\mathrm{ZnO}$ nanostructures, such as nanowires/nanorods, because the controlled morphology has a significant effect on the working performance of the nanoscale-based optoelectronics devices. Several growth methods have been utilized for the fabrication of well-aligned $1 \mathrm{D} \mathrm{ZnO}$ nanostructures such as the vapor-liquid-solid (VLS) technique [9], chemical vapor deposition (CVD) [10,11], electrochemical deposition (ED) [12], and hydrothermal methods [13-17]. The CVD and ED techniques are highly sensitive, with very demanding conditions, including the need for a single crystalline substrate [9-12]. In addition to this, a catalyst and a high temperature of $890{ }^{\circ} \mathrm{C}$ for VLS [9] and $500{ }^{\circ} \mathrm{C}$ for CVD [10] are required for the growth of nanorods. However, the hydrothermal approach has several advantages such as, it is cheap and simple, and gives high yield of $\mathrm{ZnO}$ on substrate. Highly oriented $\mathrm{ZnO}$ micro rods and micro tubes have been fabricated using the hydrothermal method with a hetero-nucleation approach, which provides a higher saturation ratio than a homogeneous solution does $[18,19]$.

Although the hydrothermal method has many advantages compared to the ED, VLS, and CVD methods, yet the properties exhibited by the hydrothermally synthesized $\mathrm{ZnO}$ nanorods are not much better than the properties exhibited by the nanorods fabricated by the ED, VLS, and CVD approaches. An X-ray diffraction (XRD) analysis has indicated the precise orientation of the nanorods perpendicular to the substrate by exhibiting only the characteristic diffraction peaks of 002 and 004 for the patterned arrays of the ZnO nanorods using the VLS [9], CVD [10,11], and ED [12] techniques. However, the $\mathrm{ZnO}$ nanorods synthesized by the hydrothermal growth method possessed additional diffraction peaks, including (100), (101), and (102) [13,14], which indicates a small deviation in the perpendicular orientation relative to the substrate of some portion of the $\mathrm{ZnO}$ nanorods. The control 
over the orientation, morphology, growth density and aspect ratio of the hydrothermally grown $\mathrm{ZnO}$ nanorods/nanowires is still the most debating issue among researchers.

Chitosan has the ability to bind strongly with a negatively charged surface due to its positive charge and can also make gels and complexes with polyanions. It is soluble in different acids and exhibits antibacterial and antifungal responses in addition to exhibiting biosafe and nontoxic properties [20,21]. Semiconductor nanoparticles are attractive to many researchers due to their wonderful optical, electrical, and mechanical properties. Among the several metal oxide nanoparticles, $\mathrm{ZnO}$ nanoparticles currently receive a lot of attention due to their significant contributions to applied sciences, such as in the areas of solar energy conversion, varistors, luminescence, photocatalysis, electrostatic dissipative coating, transparent UV protection films, and chemical sensors [22]. Several methods have been used for the preparation of $\mathrm{ZnO}$ nanoparticles, including sol-gel [23,24], precipitation [25], hydrothermal [26], and spray pyrolysis [27] methods.

In this paper, the $\mathrm{ZnO}$ nanoparticles were synthesized in an ethanolic medium and then mixed with a chitosan solution prepared in $1 \%$ acetic acid. The resulting composite was used as a seed layer for the fabrication of vertically aligned $\mathrm{ZnO}$ nanorods. We studied the effect of different composites of $\mathrm{ZnO}$ nanoparticles and chitosan as a seed on the alignment of the $\mathrm{ZnO}$ nanorods by keeping a constant amount of chitosan in the composite. The present study describes the potential applicability of the hybrid composite material as a seed layer for the fabrication of well-aligned $\mathrm{ZnO}$ nanorods oriented exactly perpendicular to the growing substrate.

\section{Results and Discussion}

\subsection{The XRD Study of the ZnO Nanorods Fabricated Using Different Composite Seed Layers of ZnO} Nanoparticles in a Chitosan Solution

The results obtained from the XRD study for the different composite seed layers of $\mathrm{ZnO}$ nanoparticles/chitosan for the growth of $\mathrm{ZnO}$ nanorods are shown in Figure 1a-f. In each XRD graph, a gold peak is appeared due to the gold layer on the glass substrate. Figure 1a shows the XRD pattern of the grown $\mathrm{ZnO}$ nanorods without the use of $\mathrm{ZnO}$ nanoparticles in the seed solution and it can be observed that (002) peak is very weak and the orientation of $\mathrm{ZnO}$ nanorods is remained a subject of matter. However, Figure 1b shows the (002), (100), (101), (102), (110), and (103) peaks for the ZnO nanorods fabricated using the $10 \mathrm{mg}$ of $\mathrm{ZnO}$ nanoparticles/chitosan seed layer. Although the (002) peak is very intense and demonstrates a growth pattern along the $c$-axis, other peaks are also apparent. However, as the quantity of $\mathrm{ZnO}$ nanoparticles in the seed solution increases, a dominant growth pattern along only (002) and (004) planes is observed, as shown in Figure 1e. Additionally, the intense growth along the $c$-axis direction suppressed the growth pattern in the other planes, as shown in Figure 1b,d,f. The composite seed layer of $\mathrm{ZnO}$ nanoparticles and chitosan strongly enhanced the (002) peak, and the primary growth pattern is observed only along the $c$-axis; this phenomenon is rarely observed when using the hydrothermal growth method. 
Figure 1. The $\mathrm{XRD}$ pattern of the $\mathrm{ZnO}$ nanorods grown using the seed solution of $\mathrm{ZnO}$ nanoparticles and chitosan with different amounts of $\mathrm{ZnO}$ nanoparticles (a) 0; (b) 10; (c) 30; (d) 50; (e) 70; and (f) $90 \mathrm{mg}$.
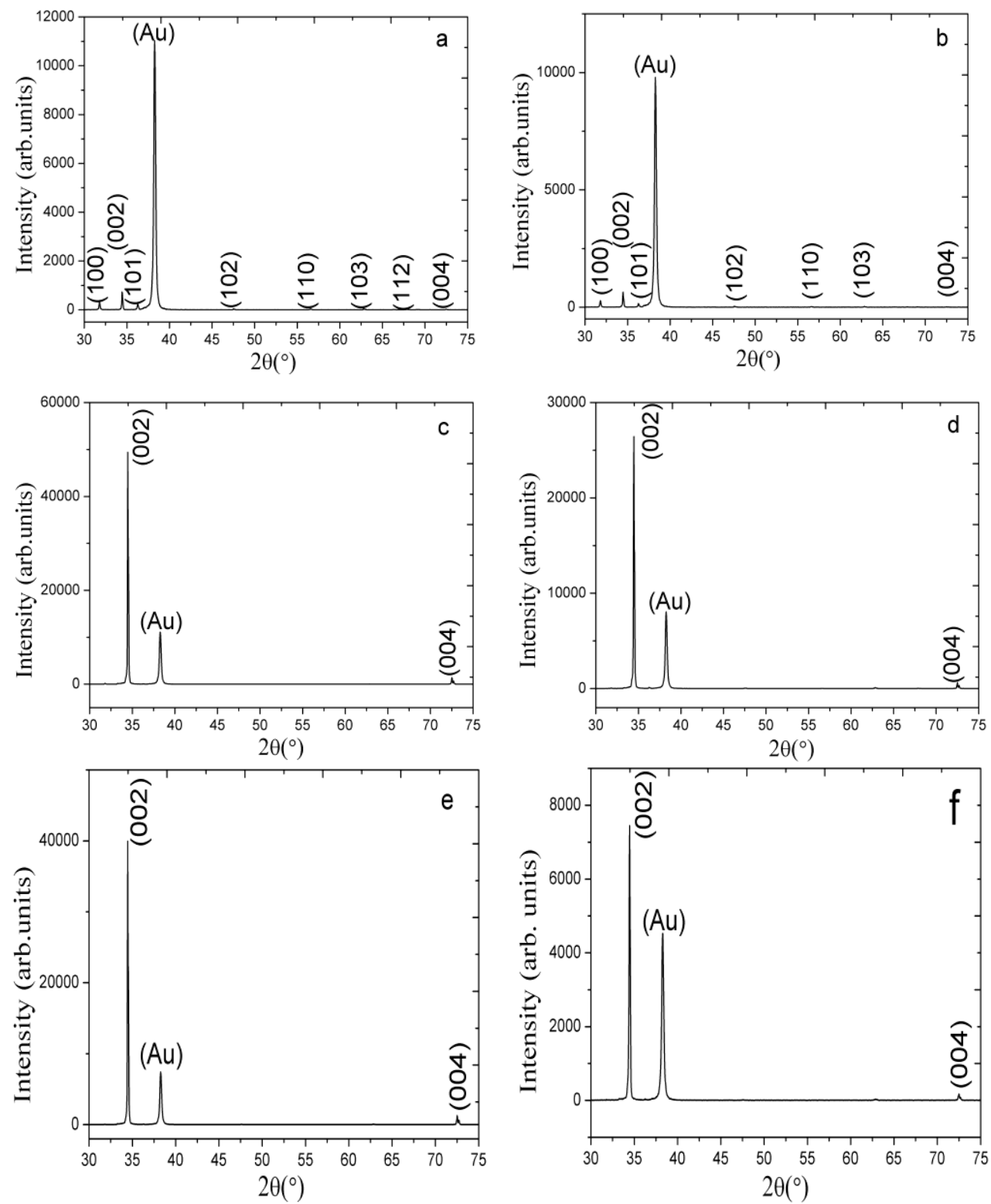

The XRD study demonstrated a good crystal quality, a wurtzite hexagonal structure and a good orientation of the $\mathrm{ZnO}$ nanorods along the $c$-axis. The possible role of chitosan in the seed layer might be as solid gel type support for the firm adhesion of seed particles on the substrate with better nucleation. We have observed during the preparation of seed solution that chitosan provides uniform distribution of $\mathrm{ZnO}$ nanoparticles, which further helps in the growth orientation of $\mathrm{ZnO}$ nanorods.

\subsection{The Morphological Study of the ZnO Nanoparticles/Chitosan Composite Seed Layer-Coated} $\mathrm{ZnO}$ Nanorods

The field emission scanning electron microscopy (FESEM) study was carried out for the fabricated $\mathrm{ZnO}$ nanorods on a gold-coated glass substrate with different composite seed layers of $\mathrm{ZnO}$ nanoparticles/chitosan, as shown in Figure $2 \mathrm{a}-\mathrm{f}$. It has been reported that the seed layer contributes to 
the growth of highly oriented $\mathrm{ZnO}$ nanorods on the substrate [28-32]. This contribution can be inferred from Figure 2a, which shows the growth pattern of the $\mathrm{ZnO}$ nanorods on a seed layer of only chitosan. These results show the random growth of the $\mathrm{ZnO}$ nanorods with a low yield. However, when $10 \mathrm{mg}$ of $\mathrm{ZnO}$ nanoparticles is used in the chitosan solution, an improved alignment in the $\mathrm{ZnO}$ nanorods is achieved, as shown in Figure 2b. Furthermore, when the amount of $\mathrm{ZnO}$ nanoparticles in the chitosan solution is increased to $30 \mathrm{mg}$, a better alignment of the $\mathrm{ZnO}$ nanorods with high density on the gold-coated glass substrate is observed, as shown in Figure 2c. A similar growth trend was observed for the composite seed layers prepared with 50, 70, and $90 \mathrm{mg}$ of $\mathrm{ZnO}$ nanoparticles in the chitosan solution, as shown in Figure $2 \mathrm{~d}-\mathrm{f}$. This growth pattern might be due initially to the uniform distribution of the $\mathrm{ZnO}$ nanoparticles in the chitosan solution and, subsequently, to the substrate-provided well nucleation sites for the synthesis of well-aligned and controlled $\mathrm{ZnO}$ nanorods. In addition to the top view FESEM images, a cross-sectional FESEM image was taken to confirm the growth pattern of the $\mathrm{ZnO}$ nanorods on the surface of the substrate, as shown in Figure $2 \mathrm{~g}$. It can be observed from this figure that the $\mathrm{ZnO}$ nanorods are $99 \%$ perpendicular to the substrate, and the measured length of the nanorod was approximately $7.1 \mu \mathrm{m}$ with average diameter of $100 \mathrm{~nm}$. The use of the composite seed layer of $\mathrm{ZnO}$ nanoparticles and chitosan has suggested a dual advantage of a seed layer composite: one advantage is the nucleation provided by the $\mathrm{Zn}$ and $\mathrm{O}$ ions of the $\mathrm{ZnO}$ nanoparticles, and the other advantage is that chitosan causes a uniform distribution of these nanoparticles on the substrate. Moreover, a combined cluster of the $\mathrm{ZnO}$ nanoparticles on the substrate [16] might be responsible for the number of $\mathrm{ZnO}$ nanorods with excellent alignment and density. Figure $2 \mathrm{~h}$ shows the energy-dispersive $\mathrm{x}$-ray (EDX) study of the $\mathrm{ZnO}$ nanorods fabricated using the composite seed layer of $\mathrm{ZnO}$ nanoparticles/chitosan. It can be observed from Figure 2 that the nanorods are only composed of $\mathrm{Zn}$ and $\mathrm{O}$ atoms, however, some amount of carbon atoms also appears in the graph, which may be due to the presence of carbon in chitosan. Chitosan is composed of carbon, hydrogen, oxygen, and nitrogen atoms, but these elements do not appear in the EDX graph because of the low percentage of these atoms in the chitosan molecule.

The experimental results of the high-resolution transmission electron microscopy (HRTEM) analysis and selected-area electron diffraction for a single crystal $\mathrm{ZnO}$ nanorod are shown in Figure $3 \mathrm{a}$. The HRTEM image indicated that the as-obtained $\mathrm{ZnO}$ nanorod is a single crystal with a wurtzite crystal structure and that the growth direction is along the (001) plane, as shown in Figure $3 \mathrm{~b}$. The HRTEM results obtained are in good agreement with the XRD results. The HRTEM study demonstrated that the $\mathrm{ZnO}$ nanorod exhibits a more pronounced lattice spacing of $26 \AA$, which is correlated with the (002) lattice spacing of the hexagonal structure of a crystalline $\mathrm{ZnO}$ nanorod, as shown in Figure 3c. The diameter of nanorod observed by the HRTEM analysis is about $90 \mathrm{~nm}$, which is relatively comparable to the diameter measured from FESEM analysis. This analysis revealed the same results as the XRD analysis did, which indicates the single crystal nature of the fabricated $\mathrm{ZnO}$ nanorods and the preferred orientation of growth along the $c$-axis when using the composite seed layer of $\mathrm{ZnO}$ nanoparticles and chitosan. 
Figure 2. The FESEM image of the $\mathrm{ZnO}$ nanorods grown using a seed solution of chitosan with different amounts of $\mathrm{ZnO}$ nanoparticles. (a) 0; (b) 10; (c) 30; (d) 50; (e) 70; (f) 90; (g) the cross-sectional image of the $\mathrm{ZnO}$ nanorods grown using the seed solution ( $90 \mathrm{mg}$ of $\mathrm{ZnO}$ nanoparticle); and (h) The EDX spectrum of the $\mathrm{ZnO}$ nanorods grown by using the seed solution of $\mathrm{ZnO}$ nanoparticles containing $70 \mathrm{mg}$ of $\mathrm{ZnO}$ nanoparticles in the chitosan solution.

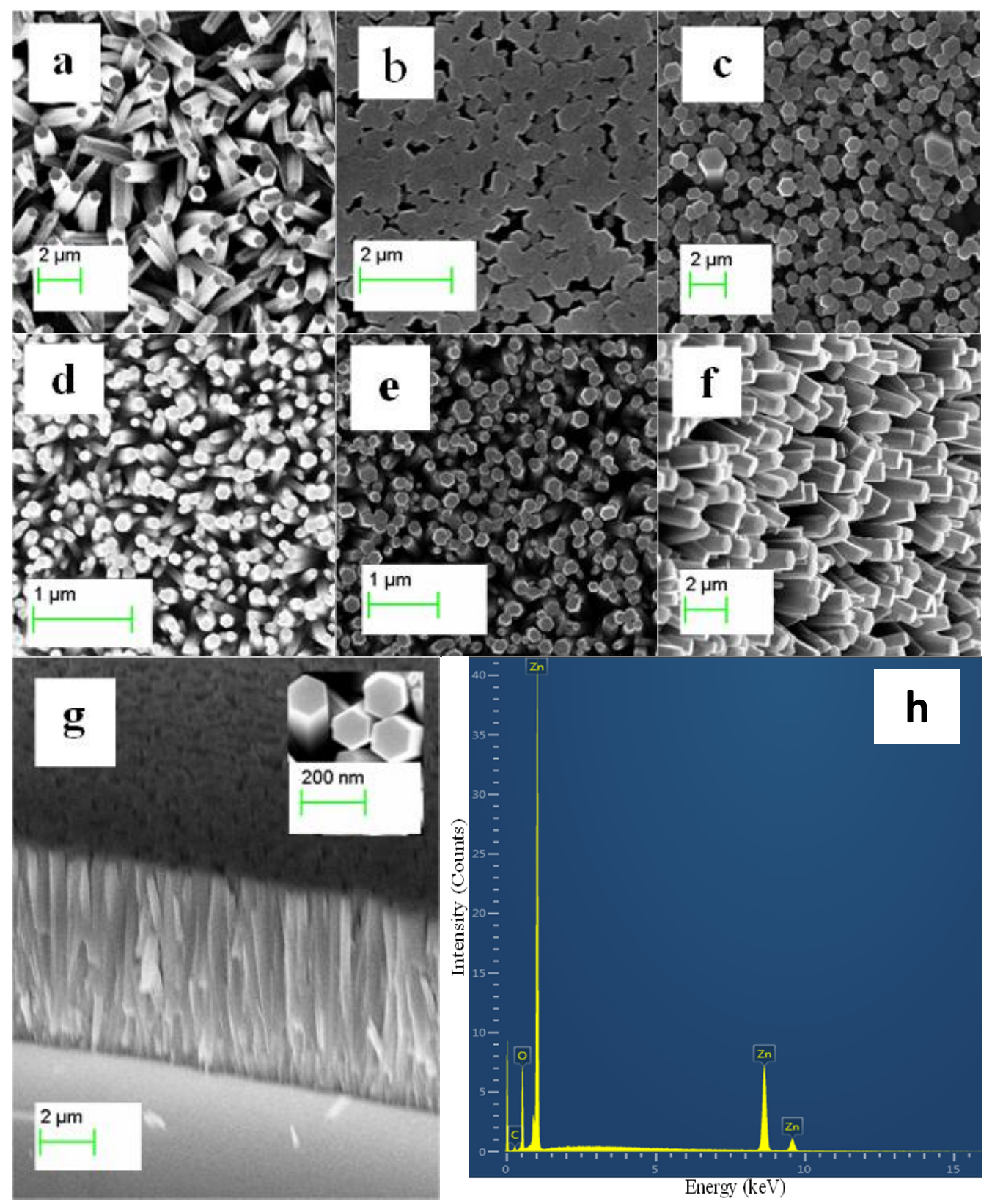


Figure 3. The HRTEM image of the $\mathrm{ZnO}$ nanorod grown with the seed solution of $70 \mathrm{mg}$ of $\mathrm{ZnO}$ nanoparticles present in the chitosan solution.

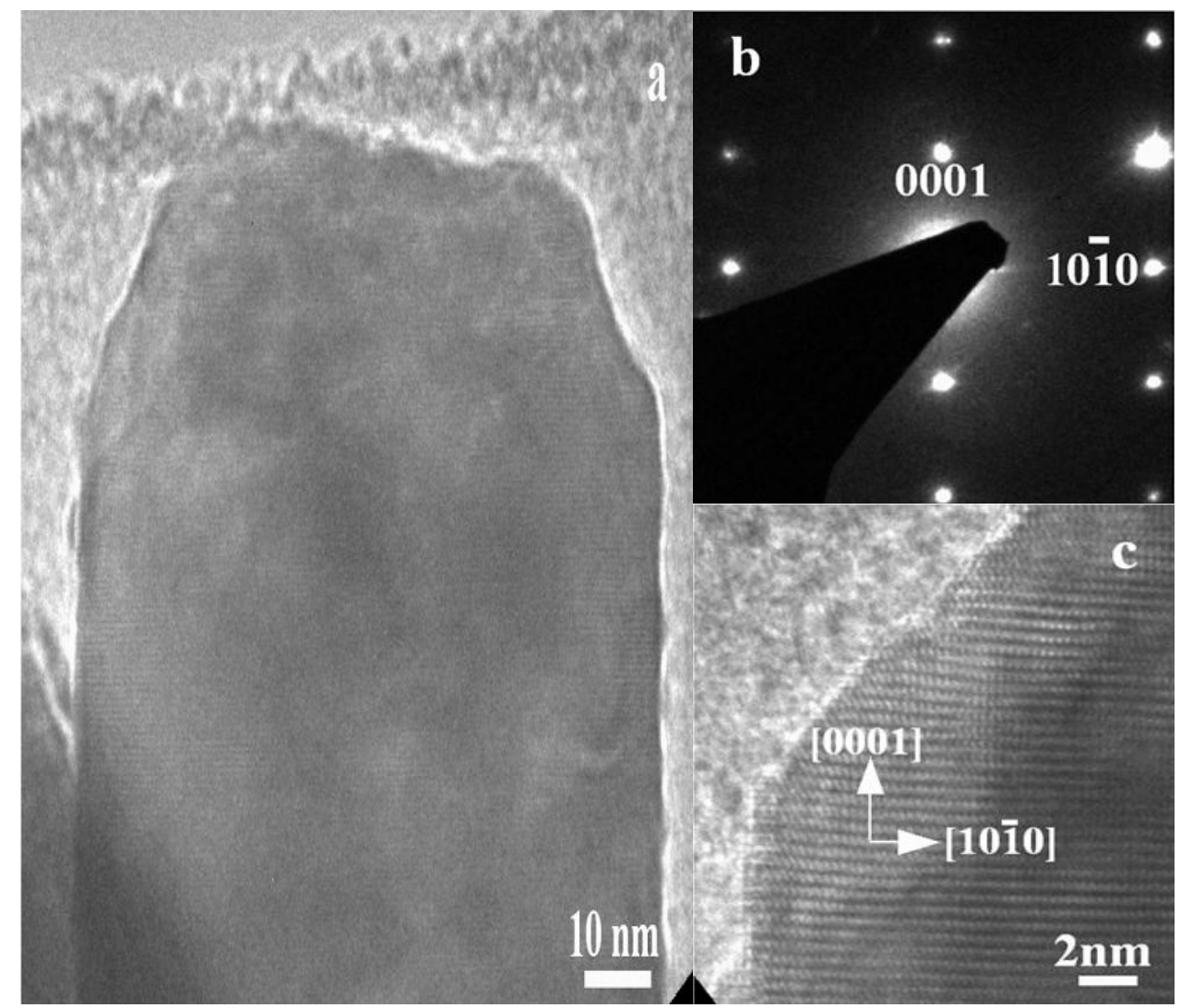

\subsection{The Atomic Force Microscopic Study of the Composite Seed of ZnO Nanoparticles and Chitosan}

A comfortable and easy heterogeneous nucleation on other surfaces has been reported in previous work [19], however, nucleation on a used substrate by providing a seed layer of $\mathrm{ZnO}$ nanoparticles is a simpler and more suitable method. This approach of using $\mathrm{ZnO}$ nanoparticles as a seed layer prior to the growth of $\mathrm{ZnO}$ nanorods has a direct effect on the morphology of the nanorods. An effective way to control the alignment and diameter of the fabricated $\mathrm{ZnO}$ nanorod arrays is always appreciated. Therefore, in the present study, an approach with a seed layer coating was used for the fabrication of well-aligned $\mathrm{ZnO}$ nanorods with a controlled diameter. The seed layer used in this study is a composite of freshly prepared $\mathrm{ZnO}$ nanoparticles and chitosan. The composite seed layer of $\mathrm{ZnO}$ nanoparticles and chitosan that was deposited on the substrate prior to the growth of the $\mathrm{ZnO}$ nanorods and was examined by atomic force microscopy (AFM), as shown in Figure 4. It can be inferred from Figure 2 that the $\mathrm{ZnO}$ nanoparticles are very well dispersed on the substrate and that the distribution of the nanoparticles on the surface is almost uniform with good nucleation sites for the controlled growth of $\mathrm{ZnO}$ nanorods. 
Figure 4. The AFM image of the $70 \mathrm{mg} \mathrm{ZnO}$ nanoparticles present in the chitosan solution.

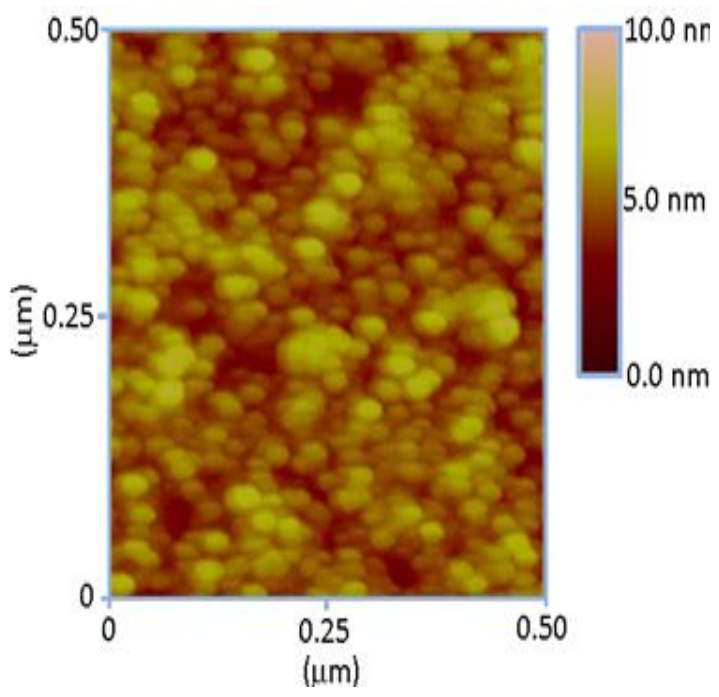

\subsection{The (Fourier Transform Infrared Spectroscopy) FTIR Study of the Fabricated ZnO Nanorods}

The FTIR experiment of the fabricated $\mathrm{ZnO}$ nanorods was performed in two different frequency ranges, as shown in Figure 5a,b. Figure 5a shows the spectrum measured in the $400-4000 \mathrm{~cm}^{-1}$ range at room temperature. The peak at $3404 \mathrm{~cm}^{-1}$ is attributed to vibrations of the $\mathrm{O}-\mathrm{H}$ group and it is due to the absorption of water molecules during the growth time; the peak at $2806 \mathrm{~cm}^{-1}$ may be due to the $\mathrm{C}-\mathrm{H}$ stretching mode. The peak at $1613 \mathrm{~cm}^{-1}$ is related to the $\mathrm{C}=\mathrm{O}$ stretching vibration and that at $1046 \mathrm{~cm}^{-1}$ corresponds to the $\mathrm{C}-\mathrm{O}$ stretching mode. Additionally, in Figure 5b, the FTIR spectrum in the $400-750 \mathrm{~cm}^{-1}$ range is shown, and characteristic peaks for the $\mathrm{Zn}-\mathrm{O}$ modes are observed. Peaks at $406-512 \mathrm{~cm}^{-1}$ are characteristic of $\mathrm{ZnO}$ [33], and we observed peaks at approximately $408-530 \mathrm{~cm}^{-1}$ that can be assigned to the $\mathrm{Zn}-\mathrm{O}$ stretching vibration modes of the $\mathrm{ZnO}$ nanorods.

Figure 5. The FTIR spectrum of the $\mathrm{ZnO}$ nanorods grown with the seed solution of $70 \mathrm{mg}$ of $\mathrm{ZnO}$ nanoparticles present in the chitosan solution at different frequency ranges (a) $400-4000 \mathrm{~cm}^{-1}$; and (b) $400-750 \mathrm{~cm}^{-1}$.
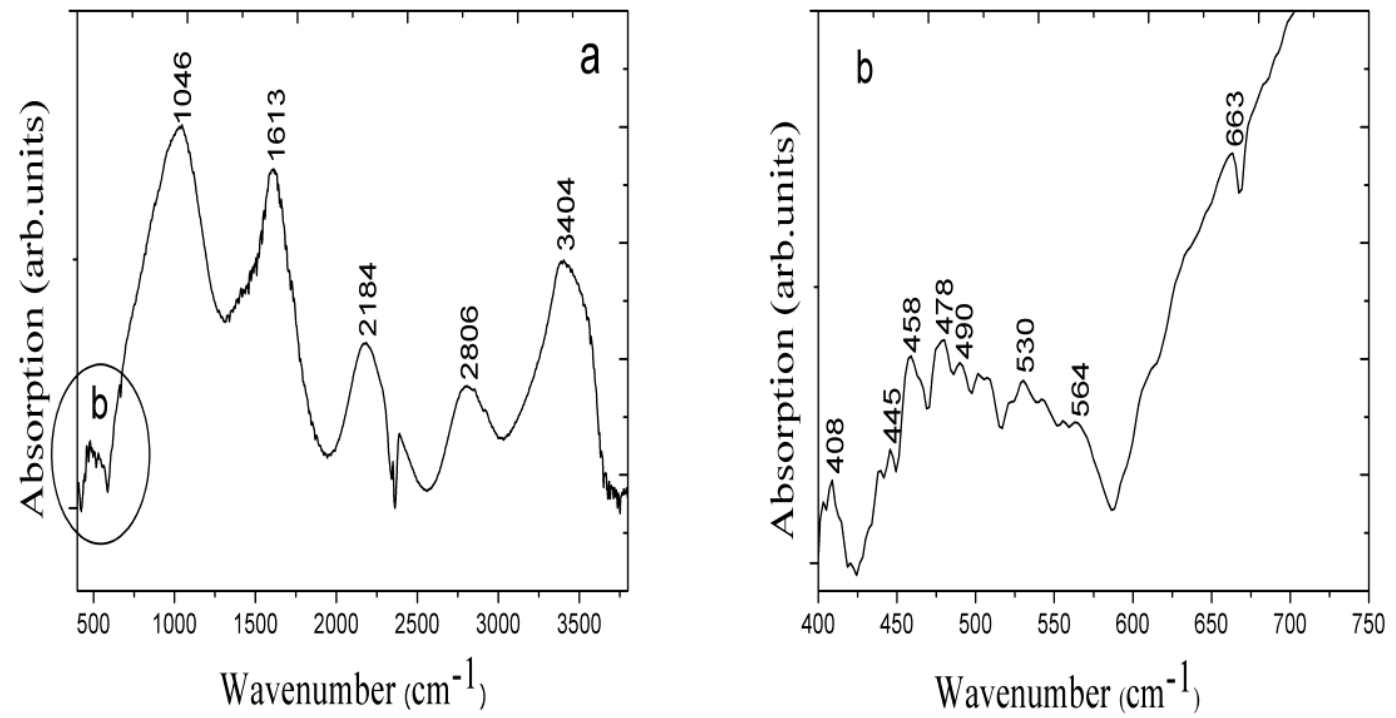


\subsection{Raman Spectroscopic Study of the As-Synthesized ZnO Nanoparticles}

The Raman study was carried out for the characterization of synthesized $\mathrm{ZnO}$ nanoparticles and Raman spectrum is shown in Figure 6. The characteristic $\mathrm{ZnO}$ nanoparticles peaks were observed in the Raman spectrum at 220,323,437, and $620 \mathrm{~cm}^{-1}$. The peak at approximately $332 \mathrm{~cm}^{-1}$ can be assigned to the second-order structure of $\mathrm{ZnO}$, and the peak at $437 \mathrm{~cm}^{-1}$ is attributed to the $\mathrm{E} 2$ mode.

Figure 6. The Raman spectrum of the $\mathrm{ZnO}$ nanoparticles at room temperature at $488 \mathrm{~nm}$.

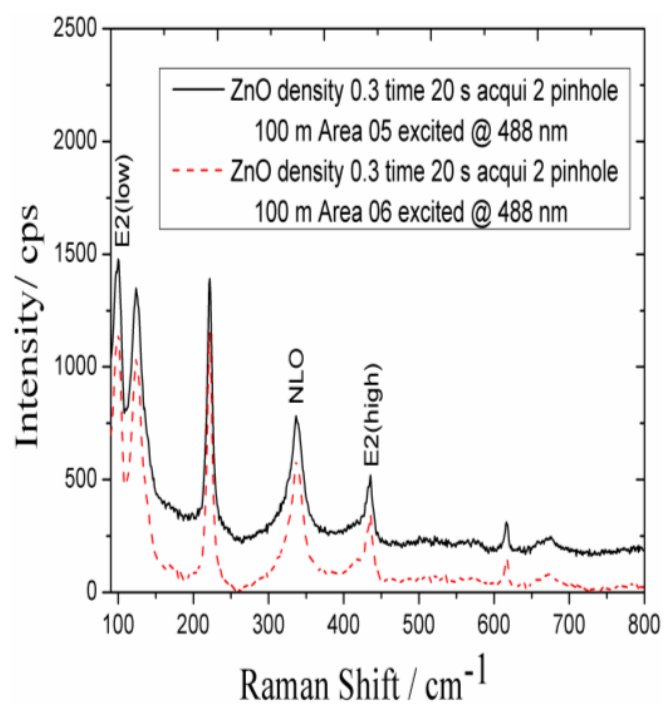

2.6. The Photoluminescence Study of the ZnO Nanoparticles/Chitosan Composite Seed Layer-Based $\mathrm{ZnO}$ Nanorods

A photoluminescence study was carried out for the $\mathrm{ZnO}$ nanorods that were fabricated using the composite seed layer of $\mathrm{ZnO}$ nanoparticles/chitosan at room temperature, and the obtained results are shown in Figure 7.

Figure 7. The photoluminescence (PL) spectrum of the $\mathrm{ZnO}$ nanorods grown with the seed solution of $70 \mathrm{mg}$ of $\mathrm{ZnO}$ nanoparticles present in the chitosan solution and with the seed layer of zinc acetate dihydrate.

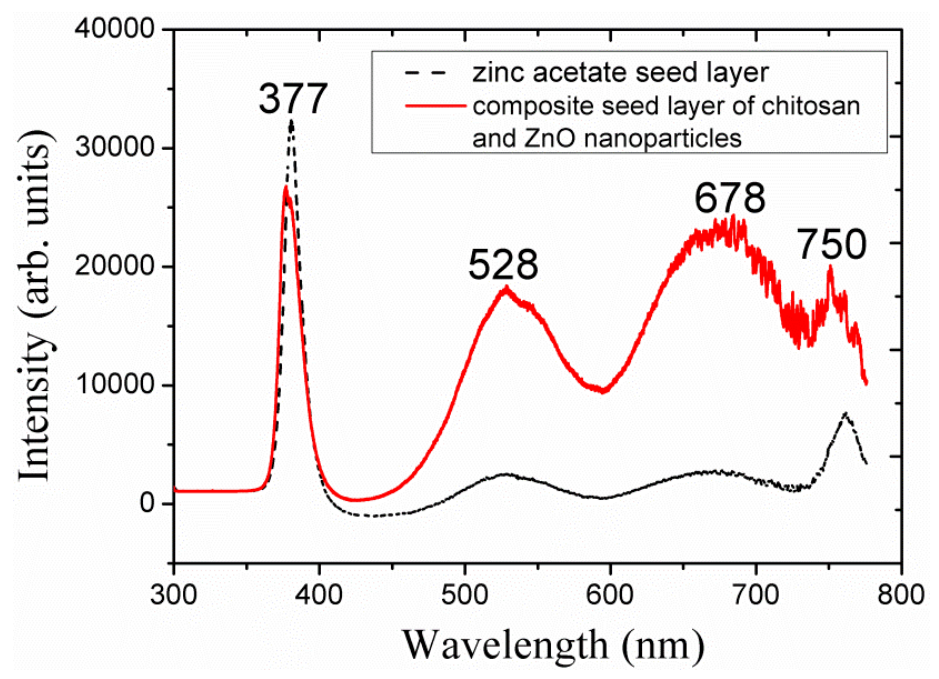


Three types of peaks can be observed in Figure 7: a strong UV peak is observed at $377 \mathrm{~nm}$; a green emission peak appeared at $528 \mathrm{~nm}$; and orange/red emission peaks are observed at 676 and $750 \mathrm{~nm}$. The broader green emission peak can be assigned to oxygen vacancies [34], and the broader orange/red emission peak may be due to the interstitial atomic defects in the $\mathrm{ZnO}$ [16]. A PL spectrum for the $\mathrm{ZnO}$ nanorods grown with the seed layer of zinc acetate dihydrate is shown with dotted lines for the comparison. From the PL spectra it is observed that the grown $\mathrm{ZnO}$ nanorods with a composite seed layer of $\mathrm{ZnO}$ nanoparticles/chitosan exhibited more defect levels compared to the $\mathrm{ZnO}$ nanorods grown with seed layer of zinc acetate dihydrate. Therefore, $\mathrm{ZnO}$ nanorods grown with a composite seed layer of $\mathrm{ZnO}$ nanoparticles/chitosan exhibit intense luminescence properties in the visible region.

\section{Materials and Experimental Section}

\subsection{Chemicals Used}

Zinc nitrate hexahydrate, hexamethylenetetramine, acetic acid, chitosan, lithium hydroxide monohydrate, zinc acetate dihydrate, and ethyl alcohol were purchased from Sigma Aldrich (Stockholm, Sweden) and were used without further purification.

\subsection{Preparation of the $\mathrm{ZnO}$ Nanoparticles}

The $\mathrm{ZnO}$ nanoparticles were prepared according to previously described methods [35]. Briefly, zinc acetate dihydrate was dissolved in $75 \mathrm{~mL}$ of ethyl alcohol and mixed with the ethanolic solution of lithium hydroxide monohydrate $\left(\mathrm{LiOH} \cdot \mathrm{H}_{2} \mathrm{O}\right)$ at room temperature with continuous stirring for approximately 8 hours. The role of lithium hydroxide monohydrate $\left(\mathrm{LiOH} \cdot \mathrm{H}_{2} \mathrm{O}\right.$, molecular weight $=41.96$ was used to hydrolyze the precursor. The mixing of $\mathrm{LiOH}$ to the transparent precursor leads to the formation of $\mathrm{ZnO}$ nanoparticles sol along with the reaction products like lithium acetate and $\mathrm{H}_{2} \mathrm{O}$ through hydrolysis. Presence of water plays an important role in growth of $\mathrm{ZnO}$ nanoparticles, and therefore presence of water is strictly controlled during the reaction and during precipitation to obtain nanopowder. The prepared $\mathrm{ZnO}$ nanoparticles were retrieved from the colloidal solution using hexane as a precipitating agent. Finally, the obtained product was dried under vacuum conditions.

\subsection{Preparation of the Composite Seed Solution of ZnO Nanoparticles and Chitosan}

Different composite seed solutions of $\mathrm{ZnO}$ nanoparticles and chitosan were prepared by mixing 10 , 30, 50, 70, and $90 \mathrm{mg}$ of the $\mathrm{ZnO}$ nanoparticles in the chitosan solution. The chitosan solution was prepared by dissolving $35 \mathrm{mg}$ of chitosan in $1 \%$ acetic acid. A homogeneous seed solution was obtained by sonication. Additionally, a chitosan solution without $\mathrm{ZnO}$ nanoparticles was used as a seed layer to confirm the role of the $\mathrm{ZnO}$ nanoparticles in the growth of the $\mathrm{ZnO}$ nanorods.

\subsection{The Growth of the ZnO Nanorods on a Gold-Coated Glass Substrate}

The $\mathrm{ZnO}$ nanorods were fabricated on a gold-coated substrate using the hydrothermal growth method, and each step of the growth is as follows: 
A Satis evaporator (725) was used to coat the gold layer onto the glass substrates. The glass substrates were affixed in the Satis evaporation chamber, and a $20 \mathrm{~nm}$ thick adhesive layer of titanium for gold was deposited. Following this, a $100 \mathrm{~nm}$ thick gold layer was evaporated. Subsequently, the gold-coated glass substrates were washed with isopropanol for 10 minutes in an ultrasonic bath and cleaned with the deionized water. The substrates were then dried in air at room temperature. The substrates were spin coated with the composite seed layer of $\mathrm{ZnO}$ nanoparticles and chitosan 2 to 4 times at $3000 \mathrm{rpm}$. The seed layer-coated substrates were annealed at $120{ }^{\circ} \mathrm{C}$ for $20 \mathrm{~min}$, affixed in a Teflon sample holder and vertically dipped into an equimolar solution of $0.075 \mathrm{M}$ zinc nitrate hexahydrate and hexamethylenetetramine. The growth solution containing the annealed substrates was kept in a preheated oven at $95{ }^{\circ} \mathrm{C}$ for 4 to 7 hours. Finally, after completion of the growth time, the substrates were removed from the oven and cleaned with deionized water to remove the solid residue particles from the surface of the $\mathrm{ZnO}$ nanostructures.

\subsection{Characterization of the As-Synthesized ZnO Nanostructures}

The synthesized $\mathrm{ZnO}$ nanoparticles were studied by Raman spectroscopy, and the composite seed layer-coated gold-coated glass substrate was studied by AFM. The AFM analysis was using Veeco Dimension 3100 (Veeco Instruments, Inc., Plainview, NY, USA), operation in tapping mode and the silicon tip (resistivity $0.01-0.025 \Omega \cdot \mathrm{cm}$; cantilever $\mathrm{T}=3.95-4.71 \mu \mathrm{m} ; \mathrm{W}=29-31 \mu \mathrm{m} ; \mathrm{L}=124 \mu \mathrm{m}$; $\mathrm{C}=39-71 \mathrm{~N} / \mathrm{m}$; and $\mathrm{f}_{0}=330-399 \mathrm{kHz}$ ). The $\mathrm{ZnO}$ nanorods were characterized by FESEM that was performed using LEO $1550 \mathrm{Gemini}$, field emission gun was operated at $20 \mathrm{kV}$. The XRD scans (0.1/s) were carried out on Phillips PW 1729 powder diffractometer using the $\mathrm{Cu}$ Ka radiation $(\lambda=1.5418 \AA)$ for the study of crystal arrays of $\mathrm{ZnO}$ nanorods. A HRTEM analysis was performed using an FEI Tecnai G2 TF20 UT (Hillsboro, OR, USA) with a field emission gun operating at $200 \mathrm{kV}$ and a point resolution of $1.9 \AA$ and equipped with an EDX. A FTIR was used for the investigation of the $\mathrm{Zn}-\mathrm{O}$ bonding. An optical study was performed using a PL technique at room temperature. In the photoluminescence experiment third harmonics $\left(\lambda_{\mathrm{e}}=266 \mathrm{~nm}\right)$ from a Coherent Ti: sapphire laser was employed and the detection was observed with Hamamatsu CCD camera. For the dispersion of PL signal a single monochromator of $1 \mathrm{~m}$ focal length (model Brucker Optics Chromex 25, Bruker Corp., Billerica, MA, USA) was associated to diffraction grating of 150 lines $/ \mathrm{mm}$.

\section{Conclusions}

In this study, $\mathrm{ZnO}$ nanorods were fabricated by a hydrothermal growth method using a composite seed layer of inorganic and organic materials. The seed layer was composed of the inorganic $\mathrm{ZnO}$ nanoparticles and the organic chitosan-conducting polymer. Different composite seed layers were prepared and used for the synthesis of the ZnO nanorods. FESEM, EDX, HRTEM, XRD, and FTIR techniques were used for the structural characterization of the $\mathrm{ZnO}$ nanorods, and these experiments explored the improved alignment, high density, and c-axis orientation of growth of the $\mathrm{ZnO}$ nanorods. Moreover, a PL study was used to determine the optical properties of these materials, and the measured results are consistent with the XRD results. This study has provided an excellent way to fabricate $\mathrm{ZnO}$ nanorods with excellent alignment and proper orientation relative to the substrate using a low-temperature, low-cost, simple and aqueous chemical growth method those results in a high yield 
of the desired nanomaterial. The obtained results indicate that the use of this method can potentially increase the performance of optoelectronic devices based on $\mathrm{ZnO}$ nanorods on the nanoscale, where alignment of nanostructures has significant contribution.

\section{Acknowledgments}

We are thankful to International Science Program (ISP), Uppsala University, Sweden; Royal University of Phnom Penh (RUPP), Cambodia; and also the Deanship of Scientific Research at King Saud University through the research group project number: RGP-VPP 023, who financially supported this research work.

\section{Conflicts of Interest}

The authors declare no conflict of interest.

\section{References}

1. Polsongkram, D.; Channinok, P.; Purkird, S.; Chow, L.; Lupan, O.; Chai, G.; Khallaf, H.; Park, S.; Schulte, A. Effect of synthesis conditions on the growth of $\mathrm{ZnO}$ nanorods via hydrothermal method. Phys. B Phys. Condens. Matter 2008, 403, 3713-3717.

2. King, D.S.; Nix, R.M. Thermal stability and reducibility of $\mathrm{ZnO}$ and $\mathrm{Cu} / \mathrm{ZnO}$ catalysts. J. Catal. 1996, 160, 76-83.

3. Zhong, J.; Kitai, A.H.; Mascher, P.; Puff, W.J. The influence of processing conditions on point defects and luminescence centers in ZnO. Electrochem. Soc. 1993, 140, 3644-3649.

4. Cao, H.; Xu, J.Y.; Zhang, D.Z.; Chang, S.H.; Ho, S.T.; Seelig, E.W.; Liu, X.; Chang, R.P.H. Spatial confinement of laser light in active random media. Phys. Rev. Lett. 2000, 84, 5584-5587.

5. Bagnall, D.M.; Chen, Y.F.; Zhu, Z.; Yao, T.; Koyama, S.; Shen, M.Y.; Goto, T. Optically pumped lasing of $\mathrm{ZnO}$ at room temperature. Appl. Phys. Lett. 1997, 70, 2230-2232.

6. Sales, B.C. Electron crystals and phonon glasses: A new path to improved thermoelectric materials. Mater. Res. Soc. Bull. 1998, 23, 15-21.

7. Trivikrama Rao, G.S.; Tarakarama Rao, D. Gas sensitivity of $\mathrm{ZnO}$ based thick film sensor to $\mathrm{NH}_{3}$ at room temperature. Sens. Actuators B 1999, 55, 166-169.

8. Agarwal, G.; Speyr, R.F. Current change method of reducing gas sensing using ZnO varistors. J. Electrochem. Soc. 1998, 145, 2920-2925.

9. Huang, M.H.; Mao, S.; Feick, H.; Yan, H.; Wu, Y.; Kind, H.; Weber, E.; Russo, R.; Yang, P. Room-temperature ultraviolet nanowire nanolasers. Science 2001, 292, 1897-1899.

10. Wu, J.J.; Liu, S.C. Low-temperature growth of well-aligned $\mathrm{ZnO}$ nanorods by chemical vapor deposition. Adv. Mater. 2002, 14, 215-218.

11. Wu, J.J.; Liu, S.C. Catalyst-free growth and characterization of $\mathrm{ZnO}$ nanorods. J. Phys. Chem. $B$ 2002, 106, 9546-9551.

12. Liu, R.; Vertegel, A.A.; Bohannan, E.W.; Sorenson, T.A.; Switzer, J.A. Epitaxial electrodeposition of $\mathrm{ZnO}$ nanopillars on single-crystal gold. Chem. Mater. 2001, 13, 508-512. 
13. Govender, K.; Boyle, D.S.; Brien, P.O.; Brinks, D.; West, D.; Coleman, D. Room-temperature lasing observed from $\mathrm{ZnO}$ nanocolumns grown by aqueous solution deposition. Adv. Mater. 2002, $14,1221-1224$.

14. Vayssieres, L. Growth of arrayed nanorods and nanowires of $\mathrm{ZnO}$ from aqueous solutions. Adv. Mater. 2003, 15, 464-466.

15. Yamabi, S.; Imai, H. Growth conditions for wurtzite zinc oxide films in aqueous solutions. J. Mater. Chem. 2002, 12, 3773-3778.

16. Greene, L.E.; Law, M.; Goldberger, J.; Kim, F.; Johnson, J.C.; Zhang, Y.; Saykally, R.J.; Yang, P. Low-temperature wafer-scale production of $\mathrm{ZnO}$ nanowire arrays. Angew. Chem. Int. Ed. 2003, 42, 3031-3034.

17. Guoa, M.; Diao, P.; Cai, S. Hydrothermal growth of well-aligned $\mathrm{ZnO}$ nanorod arrays: Dependence of morphology and alignment ordering upon preparing conditions. J. Solid State Chem. 2005, 178, 1864-1873.

18. Vayssieres, L.; Keis, K.; Lindquist, S.E.; Hagfeldt, A. Purpose-built anisotropic metal oxide material: 3D highly oriented microrod array of ZnO. J. Phys. Chem. B 2001, 105, 3350-3352.

19. Vayssieres, L.; Keis, K.; Hagfeldt, A.; Lindquist, S.E. Three-dimensional array of highly oriented crystalline ZnO microtubes. Chem. Mater. 2001, 13, 4395-4398.

20. Agnihotri, S.A.; Mallikarjuna, N.N.; Aminabhavi, T.M. Recent advances on chitosan-based micro- and nanoparticles in drug delivery. J. Control. Release 2004, 100, 5-28.

21. Kim, S.K.; Rajapakse, N. Enzymatic production and biological activities of chitosan oligosaccharides (COS): A review. Carbohydr. Poly. 2005, 62, 357-368.

22. AbdElhady, M.M. Preparation and characterization of chitosan/zinc oxide nanoparticles for imparting antimicrobial and UV protection to cotton fabric. Int. J. Carbohydr. Chem. 2012, 2012, 840591:1-840591:6.

23. Hubbard, N.B.; Culpepper, M.L.; Howell, L.L. Actuators for micropositioners and nanopositioners. Appl. Mech. Rev. 2006, 59, 324-334.

24. Lee, H.J.; Yeo, S.Y.; Jeong, S.H. Antibacterial effect of nanosized silver colloidal solution on textile fabrics. J. Mater. Sci. 2003, 38, 2199-2204.

25. Wang, L.; Muhammed, M. Synthesis of zinc oxide nanoparticles with controlled morphology. J. Mater. Chem. 1999, 9, 2871-2878.

26. Xu, H.Y.; Wang, H.; Zhang, Y.C.; He, W.M.; Zhu, M.K.; Wang, B.; Yan, H. Hydrothermal synthesis of zinc oxide powders with controllable morphology. Ceram. Int. 2004, 30, 93-97.

27. Tani, T.; Mdler, L.; Pratsinis, S.E. Homogeneous $\mathrm{ZnO}$ nanoparticles by flame spray pyrolysis. J. Nanoparticle Res. 2002, 4, 337-343.

28. Wang, S.F.; Tseng, T.Y.; Wang, Y.R.; Wang, C.Y.; Lu, H.C. Effect of ZnO seed layers on the solution chemical growth of $\mathrm{ZnO}$ nanorod arrays. Ceram. Int. 2008, 35, 1255-1260.

29. Liou, S.C.; Hsiao, C.S.; Chen, S.Y. Growth behavior and microstructure evolution of $\mathrm{ZnO}$ nanorods grown on Si in aqueous solution. J. Cryst. Growth 2005, 274, 438-446.

30. Ahmad, U.; Riberiro, C.; Al-Hajry, A.; Yoshitake, M.; Hanh, Y.B. Growth of highly $c$-axis-oriented $\mathrm{ZnO}$ nanorods on $\mathrm{ZnO} /$ glass substrate: Growth mechanism, structural, and optical properties. J. Phys. Chem. C 2009, 113, 14715-14720. 
31. Yuan, K.; Yin, X.; Li, J.; Wu, J.; Wang, Y.; Huang, F. Preparation and DSC application of the size-tuned ZnO nanoarrays. J. Alloy Comp. 2010, 489, 694-699.

32. Vayssieres, L. An aqueous solution approach to advanced metal oxide arrays on substrates. Appl. Phys. A 2007, 89, 1-8.

33. Kleinwechter, H.; Janzen, C.; Knipping, J.; Wiggers, H.; Roth, P. Formation and properties of $\mathrm{ZnO}$ nanoparticles from gas phase synthesis processes. J. Mater. Sci. 2002, 37, 4349-4360.

34. Vanheusden, K.; Warren, W.L.; Seager, C.H.; Tallant, D.R.; Voigt, J.A.; Gnade, B.E. Mechanisms behind green photoluminescence in $\mathrm{ZnO}$ phosphor powders. J. Appl. Phys. 1996, 79, 7983-7991.

35. Raju, K.; Ajeet, K.; Pratima, R.S.; Anees, A.A.; Manoj, K.P.; Malhotra, B.D. Zinc oxide nanoparticles-chitosan composite film for cholesterol biosensor. Analytica Chimica Acta 2008, 616, 207-213.

(C) 2013 by the authors; licensee MDPI, Basel, Switzerland. This article is an open access article distributed under the terms and conditions of the Creative Commons Attribution license (http://creativecommons.org/licenses/by/3.0/). 